\title{
Septin4 regulates endoplasmic reticulum stress and apoptosis in melatonin-induced osteoblasts
}

\author{
LIN TAO ${ }^{*}$, SICHAO ZHAO* ${ }^{*}$ ZHENGBO TAO ${ }^{*}$, KAICHENG WEN, SIMING ZHOU, WACILI DA and YUE ZHU \\ Department of Orthopedics, First Affiliated Hospital of China Medical University, Shenyang, Liaoning 110001, P.R. China
}

Received November 28, 2019; Accepted April 15, 2020

DOI: $10.3892 / \mathrm{mmr} .2020 .11228$

\begin{abstract}
Idiopathic scoliosis (IS) is a spinal 3-dimensional deformity with an unknown cause. Melatonin is secreted by the pineal body and contributes to the occurrence and progression of IS. In our previous preliminary study, it was reported that high concentrations of melatonin can induce osteoblast apoptosis, thus acting as an IS treatment, but the mechanism of action is unknown. Therefore, the present study was performed to further investigate the possible mechanism underlying the efficacy of melatonin as a treatment for IS. The present results indicated that high concentrations of melatonin mediate endoplasmic reticulum stress (ERS)-induced apoptosis in hFOB 1.19 cells, and this resulted in a significant and dose-dependent increase in the expression of Septin4, as well as the expression levels of glucose-regulated protein (GRP)78, GRP94 and cleaved caspase-3. Furthermore, osteoblasts were overexpressed with Septin4 and the mechanism via which melatonin induces osteoblast ERS was demonstrated to be via the regulation of Septin4. In addition, it was indicated that cytoskeleton destruction, cell morphology changes and the decrease in the number of cells were aggravated after osteoblasts were overexpressed with Septin4, as indicated by phalloidin and DAPI staining. Collectively, the present results suggest that the Septin4 protein may be a target of ERS in melatonin-induced osteoblast apoptosis, which is involved in bone metabolism diseases, thus providing novel evidence for clinical melatonin treatment of IS.
\end{abstract}

Correspondence to: Professor Yue Zhu, Department of Orthopedics, First Affiliated Hospital of China Medical University, 155 Nan Jing North Street, Shenyang, Liaoning 110001, P.R. China E-mail: zhuyuedr@163.com

*Contributed equally

Abbreviations: IS, idiopathic scoliosis; ERS, endoplasmic reticulum stress; GRP78, glucose regulated protein 78; GRP94, glucose regulated protein 94

Key words: IS, Septin4, melatonin, hFOB 1.19, ERS, apoptosis, cytoskeleton destruction

\section{Introduction}

Idiopathic scoliosis (IS) is defined as scoliosis with an unknown cause that presents as a spinal 3-dimensional deformity during growth and development, and has an increasing prevalence (current incidence rate, $>2 \%$ ) and poses a worldwide threat to human health (1-3). The most common time for the development of IS to occur is during the fastest-growing state of juveniles (age, 10-16 years), which is the most active period of bone development and osteoblast proliferation (4-7). Moreover, effective inhibition of osteoblast proliferation and induction of apoptosis contribute to the prevention and treatment of IS (8). Therefore, medication that can induce osteoblast apoptosis should be investigated as a potential therapeutic strategy for IS. Previous studies have reported that melatonin exerts an influence on the progression of IS (9-14). Furthermore, our previous studies revealed that high concentrations of melatonin significantly inhibit osteoblast viability $(15,16)$, thus indicating a possible clinical application of melatonin in preventing and controlling the progression of IS (17); however, the mechanism is yet to be elucidated.

The endoplasmic reticulum (ER) is a critical subcellular organelle responsible for regulation of $\mathrm{Ca}^{2+}$ homoeostasis and transmembrane protein synthesis and folding $(18,19)$. External stimulation induces the disruption of ER physiological function, which triggers ER stress (ERS) (20,21). Moreover, ERS can reduce cell damage and restore cell function by activating the unfolded protein response (UPR) $(22,23)$. However, excessive or prolonged ERS can induce cell apoptosis (24-26), and it has been reported that melatonin can initiate ERS-induced apoptosis in human hepatoma cells (27). In addition, excessive ERS caused by a high concentration of melatonin is a direct factor for inducing apoptosis (28). It is also speculated that these effects be due to the high concentration of melatonin caused by $\mathrm{Ca}^{2+}$ overload and the induction of osteoblastic ERS, but this is yet to be elucidated.

The ER is highly sensitive to stress; it maintains its structure and function by regulating membrane proteins, and selectively transports membrane proteins to deliver biological effects (29). However, the type of ER target protein that melatonin interacts with to export relevant membrane proteins, transfer biological information to the cell membrane, open $\mathrm{Ca}^{2+}$ channels on the cell membrane surface and induce ERS is not yet fully understood. Golgi membranes of HeLa cells using small interfering RNA screen technology and, when exposed 
to external stimuli, will rapidly redistribute on the plasma membrane, causing $\mathrm{Ca}^{2+}$ influx in the cell membrane (30). Furthermore, it has been reported that Septin4, a subtype of the Septin superprotein family, is a necessary component of cytoskeletal proteins and may affect vesicle trafficking, apoptosis and numerous important physiological processes (31-34). The present study hypothesized that septin 4 may also be a target protein of melatonin-induced osteoblasts, activate ERS and induce apoptosis. However, the mechanism via which melatonin induces osteoblast apoptosis to regulate IS is yet to be elucidated. Therefore, the aim of the present study was to further investigate the mechanism underlying the effect of melatonin on osteoblast development and its possible target of osteoblasts, which may provide a novel insight and direction for treatment of IS.

\section{Materials and methods}

Cell culture and treatment. The clonal human fetal osteoblastic (hFOB 1.19) cell line (35) was donated by Dr Malayannan Subramaniam (Department of Biochemistry and Molecular Biology, Mayo Clinic; Rochester, USA) (36). Cells were cultured in a humidified incubator with $5 \% \mathrm{CO}_{2}$ atmosphere at $37^{\circ} \mathrm{C}$ and in a 1:1 mixture of DMEM and F-12 medium (HyClone; GE Healthcare Life Sciences) with 10\% FBS (HyClone; GE Healthcare Life Sciences) and a $100 \mu \mathrm{g} / \mathrm{ml}$ streptomycin and $100 \mathrm{U} / \mathrm{ml}$ penicillin solution (HyClone; GE Healthcare Life Sciences). The cell culture medium was changed every other day. The osteoblastic cells were sub-cultured using $0.25 \%$ trypsin with EDTA (HyClone; GE Healthcare Life Sciences) to replace the cells. Osteoblasts were cultured to passages $8-11$ and plated at $1 \times 10^{4}$ cells $/ \mathrm{cm}^{2}$ for $24 \mathrm{~h}$ before treatment. Melatonin (2,4 and $6 \mathrm{mM})$, obtained from Sigma-Aldrich (Merck KGaA), was dissolved in medium containing $0.2 \%$ DMSO and $10 \% \mathrm{FBS}$ to treat the cells for $24 \mathrm{~h}$ in $5 \% \mathrm{CO}_{2}$ at $37^{\circ} \mathrm{C}$.

Plasmids, cell transfections. The full-length human Septin4 plasmid (Shanghai Genechem Co., Ltd.) was cloned to Flag-tagged destination vectors (Shanghai Genechem Co., Ltd.) according to the requirements of immunoblotting. Cell transfections were performed using Lipofectamine ${ }^{\circledR} 2000$ ( $37^{\circ} \mathrm{C}$ for $48 \mathrm{~h}$; $90 \%$ cell density) (Invitrogen; Thermo Fisher Scientific, Inc.), according to the manufacturer's instructions. The control group comprised cells transfected with control plasmid. The time interval between transfection and subsequent experimentation was $24 \mathrm{~h}$.

Cell viability assay. Cell viability was measured using an MTT assay (Sigma-Aldrich; Merck KGaA). hFOB 1.19 cells were seeded in 96 -well plates at a density of $6 \times 10^{3}$ cells/well and allowed to adhere for $24 \mathrm{~h}$ at $37^{\circ} \mathrm{C}$ before being treated. Then, cells were transfected with the control plasmid or Flag-Septin4 plasmid. The time interval between transfection and subsequent experimentation was $24 \mathrm{~h}$. Subsequently, hFOB 1.19 cells were divided into four groups randomly: i) Transfected with control plasmid; ii) transfected with control plasmid and exposed to melatonin (2, 4 and $6 \mathrm{mM})$; iii) transfected with Flag-Septin4 plasmid; and iv) transfected with Flag-Septin4 plasmid and exposed to melatonin (2, 4 and $6 \mathrm{mM})$. The cells were transfected for $48 \mathrm{~h}$ and treated with melatonin for $48 \mathrm{~h}$ at $37^{\circ} \mathrm{C}$. Medium was replaced with $90 \mu \mathrm{l}$ fresh culture medium, and $10 \mu \mathrm{l}$ MTT $(5 \mathrm{mg} / \mathrm{ml})$ solution was added to each well. After incubation at $37^{\circ} \mathrm{C}$ for $4 \mathrm{~h}$, the supernatant was removed and $110 \mu \mathrm{l}$ DMSO was added to each well. The mixture was agitated on a plate for $10 \mathrm{~min}$ before the optical density of each well was measured at $490 \mathrm{~nm}$ using an Absorbance Reader. Data from five independent experiments were analyzed.

Annexin V-FITC/propidium iodide (PI) double-staining for cell apoptosis analysis. Apoptotic cells were detected using an Annexin V-FITC/PI kit (Dojindo Molecular Technologies, Inc.) and quantified using a BD LSRFortesa (BD Biosciences); data were analyzed using BD FACSDiva Software (version 6.2; BD Biosciences). hFOB 1.19 cells were seeded in 6-well plates at a density of $1 \times 10^{5}$ cells/well, and then the four different groups of cells were transfected for $48 \mathrm{~h}$ and treated with $4 \mathrm{mM}$ melatonin for $48 \mathrm{~h}$ at $37^{\circ} \mathrm{C}$. The treated cells were digested with $0.25 \%$ trypsin (without EDTA), centrifuged at $300 \mathrm{x} \mathrm{g}$ for $3 \mathrm{~min}$ at $4^{\circ} \mathrm{C}$ and then washed with cold PBS twice. After the supernatant had been discarded, cells were resuspended in $500 \mu \mathrm{l}$ binding buffer, and Annexin-V-FITC $(5 \mu \mathrm{l})$ and PI (5 $\mu \mathrm{l})$ were added and mixed. The suspensions were incubated in dark for $20 \mathrm{~min}$ at room temperature prior to flow cytometric analysis. Finally, cells were analyzed using a BD FACScan flow cytometer equipped with ModFit LT v3.0 (Becton, Dickinson and Company) within $1 \mathrm{~h}$. Cells were classified as follows: Viable (Annexin V-FITC-/PI-), early apoptotic (Annexin V-FITC+/PI-), late apoptotic (Annexin V-FITC+/PI+) or necrotic (Annexin V-FITC-/PI+). The experiment was repeated three times.

Western blotting. Monoclonal mouse anti-Septin4 (1:4,000; cat. no. ab166788; Abcam), polyclonal rabbit anti-glucoseregulated protein (GRP)94 (1:1,000; cat. no. ab2791; Abcam), GRP78 (1:1,000; cat. no. ab21685; Abcam), polyclone rabbit anti-caspase-3 (1:1,000; cat. no. 9662; Cell Signaling Technology, Inc.), monoclonal mouse anti-Flag (1:1,000; cat. no. 8146; Cell Signaling Technology, Inc.) and monoclonal mouse anti- $\beta$-actin (1:10,000; cat. no. 4970; ProteinTech Group, Inc.) antibodies were obtained commercially. In addition, goat anti-mouse and anti-rabbit secondary antibodies (both 1:500; cat. nos. 7076 and 4414, respectively) were purchased from Beijing Zhongshan Golden Bridge Biotechnology Co., Ltd.

Following treatment with $4 \mathrm{mM}$ melatonin for $48 \mathrm{~h}$ at $37^{\circ} \mathrm{C}$, proteins were extracted using RIPA lysis buffer (Beyotime Institute of Biotechnology) for $30 \mathrm{~min}$ at $4^{\circ} \mathrm{C}$ and centrifuged at $2,500 \mathrm{x} \mathrm{g}$ for $20 \mathrm{~min}$ at $4^{\circ} \mathrm{C}$. The supernatant fluid containing total cell lysate was harvested. The concentrations of protein were determined using the bicinchoninic acid protein assay (Beyotime Institute of Biotechnology). Each sample (60 $\mu \mathrm{g}$ protein/lane) was separated via 10\% SDS-PAGE and transferred to $0.22 \mu \mathrm{m}$ PVDF membranes at $80 \mathrm{~V}$ for $90 \mathrm{~min}$ at $4^{\circ} \mathrm{C}$. After blocking with 5\% BSA (Beyotime Institute of Biotechnology) in TBST (10\% Tween 20) at room temperature for $1 \mathrm{~h}$ and agitation for $1 \mathrm{~h}$ at $4^{\circ} \mathrm{C}$, PVDF membranes were incubated overnight with corresponding antibodies (GRP78, GRP94, Septin4, caspase-3, Flag and $\beta$-actin) at $4^{\circ} \mathrm{C}$. Subsequently, after washing four times with TBST for $15 \mathrm{~min}$ each time, membranes were visualized using goat anti-mouse 
or goat anti-rabbit IgG antibodies conjugated with horseradish peroxidase at 1:10,000 for $2 \mathrm{~h}$ at room temperature. Membranes were washed four times with TBST for $15 \mathrm{~min}$, and an EC3 Imaging system (UVP LLC) was used to scan the specific bands. All of the bands were normalized to $\beta$-actin content of the same sample and ImageJ software (version 1.51; National Institutes of Health) was used to measure the protein expression.

Phalloidin staining. Phalloidin (AAT Bioquest, Inc.) was used to stain fibrillar (F)-actin. In total, 1X Phalloidin conjugate working solution was prepared according to the manufacturer's instructions. hFOB 1.19 cells were seeded in 24 -well plates at a density of $1.2 \times 10^{4}$ cells/well and allowed to adhere for $24 \mathrm{~h}$ before being treated at $37^{\circ} \mathrm{C}$. Then, the various groups of cells were transfected for $48 \mathrm{~h}$ and treated with $4 \mathrm{mM}$ melatonin for $48 \mathrm{~h}$ at $37^{\circ} \mathrm{C}$. Subsequently, treated cells were washed three times with PBS solution and fixed using $4 \%$ paraformaldehyde for $30 \mathrm{~min}$ at room temperature. After rinsing the cells three times in PBS, $0.1 \%$ Triton X-100 in PBS was added to fixed cells for $15 \mathrm{~min}$ at room temperature to increase permeability, and then cells were washed three times with PBS. Subsequently, cells were incubated with phalloidin-conjugate working solution $(500 \mu \mathrm{l} /$ well) at room temperature in the dark for 30 min to stain the cells. After rinsing cells gently with PBS three times to remove excess phalloidin, 10\% DAPI (Beijing Solarbio Science \& Technology Co., Ltd.) was used at room temperature for $30 \mathrm{~min}$ in the dark for nucleus staining. The cells were washed again with PBS solution three times, and then were observed and imaged via fluorescence microscopy (magnification, x20) (Olympus Corporation).

Statistical analysis. Quantitative data from $\geq 3$ independent experiment were analyzed using GraphPad Prism 5 software (GraphPad Software, Inc.). Differences in data between two groups were analyzed using an independent samples t-test, and differences between multiple groups were assessed using one-way ANOVA with Tukey's test. Data are presented as the mean $\pm \mathrm{SD}$, and $\mathrm{P}<0.05$ was considered to indicate a statistically significant difference.

\section{Results}

High concentration of melatonin promotes ERS and ERS-induced apoptosis, and decreases the viability of $h F O B$ 1.19 cells. To determine the effect of different concentrations of melatonin on the viability of osteoblasts, an MTT assay was performed. Firstly, 0, 2, 4 and $6 \mathrm{mM}$ melatonin were used to treat osteoblasts for $48 \mathrm{~h}$, and it was revealed that the viability of osteoblasts decreased in association with increased melatonin concentration (Fig. 1A). In addition, compared with the control group, cells treated with higher concentrations of melatonin exhibited significantly enhanced apoptosis (Fig. 1B). Moreover, the expression levels of ERS-related genes (GRP78 and GRP94) and apoptosis-related genes (cleaved caspase-3) were significantly increased in a dose-dependent manner following a rise in melatonin concentration (Fig. 1C). Therefore, the results indicated that a high concentration of melatonin promoted ERS, which induced apoptosis and decreased the viability of osteoblasts.
Septin4 expression affects ERS and apoptosis and decreases the viability of hFOB 1.19 cells treated with a high concentration of melatonin. The present study also assessed the importance of Septin 4 in bone metabolic diseases. It was demonstrated that, compared with the control group, the expression of Septin4 in osteoblasts treated with a high concentration of melatonin was significantly increased. Moreover, the expression of Septin4 was significantly increased in a dose-dependent manner in association with melatonin concentration (Fig. 1C). Thus, the results suggested that Septin4 may be associated with melatonin-induced osteoblast apoptosis via ERS (Fig. 1).

Overexpression of Septin4 promotes apoptosis in hFOB 1.19 cells induced by treatment with a high concentration of melatonin. To further examine the effect of Septin4 on high concentration of melatonin-induced osteoblasts apoptosis, cells were transfected with control plasmid or Flag-Septin4 plasmid for $48 \mathrm{~h}$ and treated with $0,2,4$ and $6 \mathrm{mM}$ melatonin for $48 \mathrm{~h}$. It was identified that overexpression of Septin4 further inhibited osteoblast viability compared with the control plasmid (Fig. 2A). Furthermore, the results indicated that overexpression of Septin4 resulted in a significantly higher rate of apoptosis (NC with melatonin $7.63 \%$ vs. Flag-Septin4 with melatonin $18.43 \%$; $\mathrm{P}<0.001$; Fig. 2B); however, this effect was not observed in the absence of melatonin. Collectively, the results demonstrated that Septin4 significantly decreased cell viability and promoted apoptosis, following induction using a high concentration of melatonin (Fig. 2).

Overexpression of Septin4 increases ERS in hFOB 1.19 cells ERS and apoptosis pathway-associated genes expression levels induced by treatment with high concentration of melatonin. In addition, the effect of overexpressing Septin 4 on the expression levels of ERS- and apoptosis-associated pathway genes were assessed, as well as the effects induced by a high concentration of melatonin in osteoblasts. Cells were transfected with either the Flag-Septin4 plasmid or control plasmid for $48 \mathrm{~h}$ and treated with 0 or $4 \mathrm{mM}$ melatonin for $48 \mathrm{~h}$. It was identified that both the expression levels of ERS-associated genes (GRP78 and GRP94) and apoptosis-associated genes (cleaved caspase-3) were increased in the cells transfected with the Flag-Septin4 plasmid and treated with melatonin, compared with cells transfected with the control plasmid and administered melatonin (Fig. 3). However, in the absence of melatonin treatment, the expression levels of these genes were not significantly different between the Flag-Septin4 plasmid and the control plasmid. Therefore, the results indicated that Septin4 mediates ERS and osteoblast apoptosis, and its effect was dependent on treatment with melatonin (Fig. 3).

Overexpression of Septin4 increases cytoskeleton destruction induced by treatment with a high concentration of melatonin in hFOB 1.19 cells. To determine whether a high concentration of melatonin can induce cytoskeleton destruction, phalloidin was used to stain F-actin and DAPI was used for nuclei staining. Then, fluorescence microscopy was performed to analyze the staining profiles and it was revealed that F-actin was well aligned along the axis of hFOB cells in control groups (Fig. 4). However, when hFOB cells were treated with $4 \mathrm{mM}$ 
A

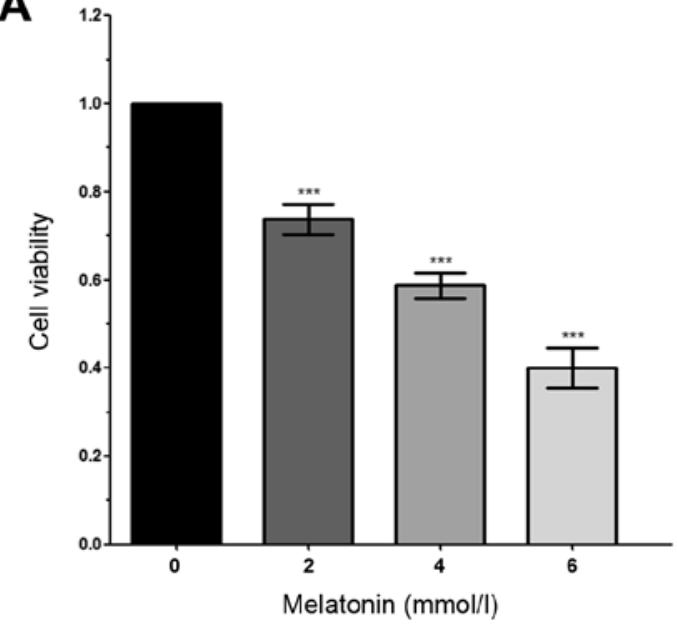

B

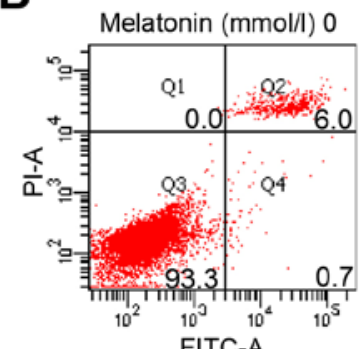

FITC-A

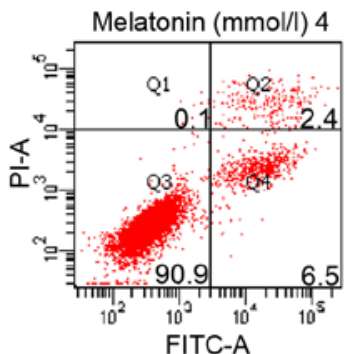

FITC-A

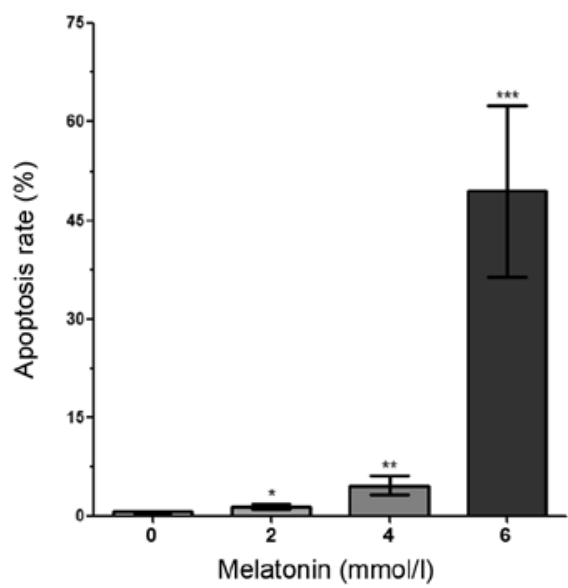

C
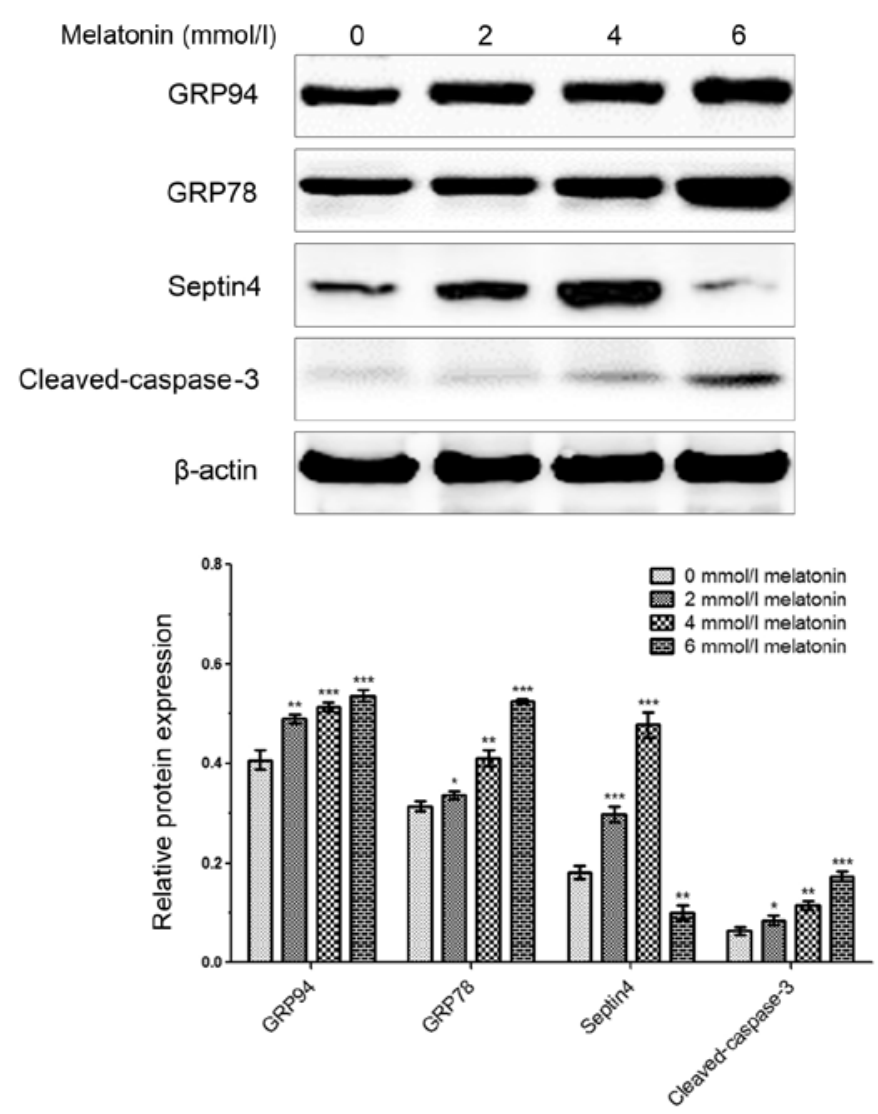

Figure 1. Expression of Septin4 is increased in hFOB 1.19 cells treated with a high concentration of melatonin. (A) hFOB 1.19 cells were treated with 0,2 , 4 and $6 \mathrm{mmol} / \mathrm{l}$ of melatonin for $48 \mathrm{~h}$. Cell viability was assessed via the MTT assay. (B) Flow cytometry was performed to analyze apoptosis in hFOB 1.19 cells, which were treated with $0,2,4$ and $6 \mathrm{mmol} / 1$ of melatonin. (C) Western blotting was performed to detect the expression levels of GRP78, GRP94, cleaved caspase- 3 and Septin 4 after treatment with $0,2,4$ and $6 \mathrm{mmol} / 1$ of melatonin for $48 \mathrm{~h} .{ }^{*} \mathrm{P}<0.05,{ }^{* *} \mathrm{P}<0.01,{ }^{* * * *} \mathrm{P}<0.001 \mathrm{vs} .0 \mathrm{mmol} / 1$ group. GRP, glucose regulated protein; PI propidium iodide.

melatonin for $48 \mathrm{~h}$, actin microfilament staining was blurry or non-existent. Moreover, the size of the cells increased, and the cell count decreased in the melatonin treatment groups. In addition, statistical analysis demonstrated that this event had a 1.39-fold increase $(\mathrm{P}<0.01)$ in cells with the overexpression Flag-Septin4 plasmid compared with those that expressed the control plasmid. Collectively, the results demonstrated that overexpression of Septin4 increased cytoskeleton destruction, 
A

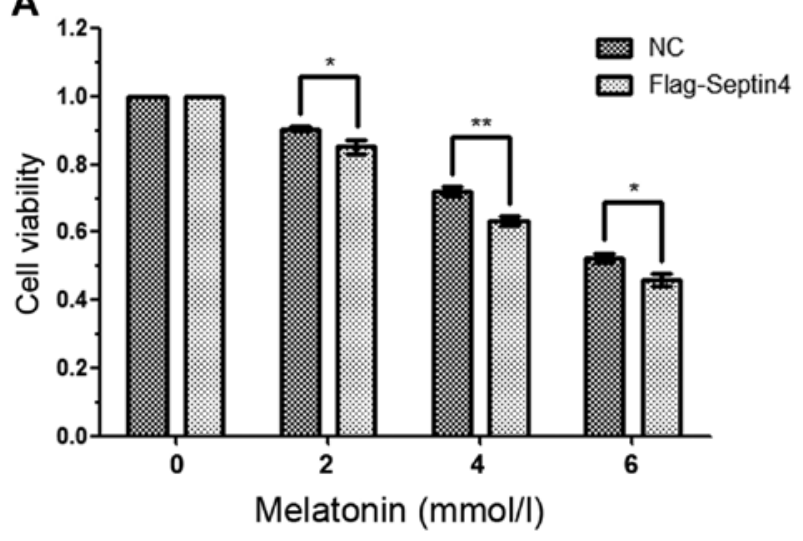

B
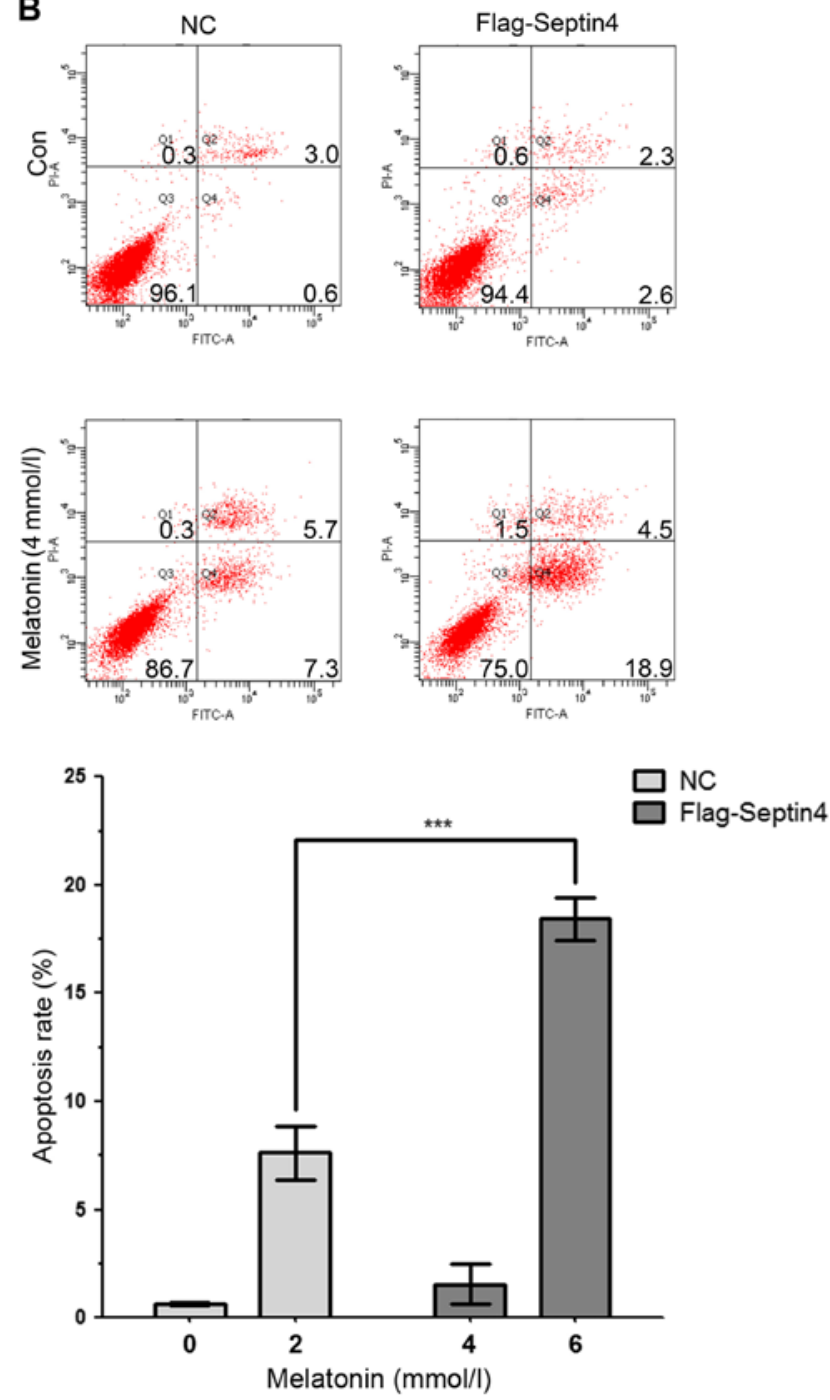

Figure 2. Overexpression of Septin4 promotes apoptosis in hFOB 1.19 cells treated with a high melatonin concentration. (A) $\mathrm{hFOB}$ cells were transfected with NC plasmid or Flag-Septin4 plasmid for $48 \mathrm{~h}$ and treated with $0,2,4$ and $6 \mathrm{mmol} / \mathrm{l}$ of melatonin for $48 \mathrm{~h}$. Cell viability was assessed via the MTT assay. (B) hFOB cells were transfected with $\mathrm{NC}$ plasmid or Flag-Septin4 plasmid for $48 \mathrm{~h}$ and treated with 0 or $4 \mathrm{mmol} / \mathrm{l}$ of melatonin for $48 \mathrm{~h}$. Flow cytometry was performed to analysis cell apoptosis ( $\mathrm{Q} 4$ region). ${ }^{*} \mathrm{P}<0.05$, ${ }^{* *} \mathrm{P}<0.01,{ }^{* * *} \mathrm{P}<0.001$, vs. NC group. GRP, glucose-regulated protein; NC, negative control; Con, control; PI, propidium iodide.

which was induced by treatment with a high concentration of melatonin in hFOB 1.19 cells. (Fig. 4).

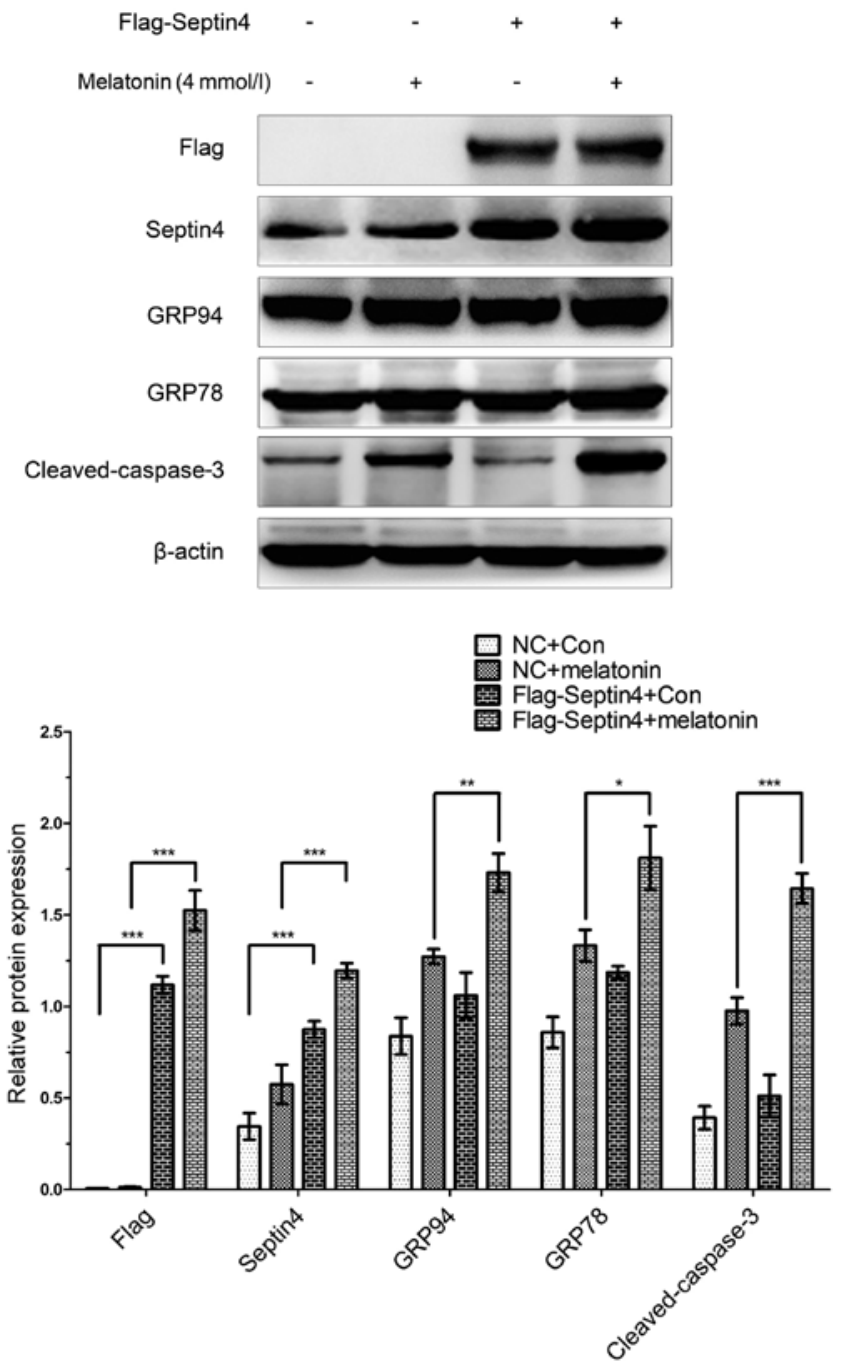

Figure 3. Overexpression of Septin4 increases ERS- and apoptosis pathway-related gene expression levels in hFOB 1.19 cells treated with a high melatonin concentration. hFOB 1.19 cells were transfected with Flag-Septin4 plasmid or NC plasmid for $48 \mathrm{~h}$ and treated with 0 or $4 \mathrm{mmol} / \mathrm{l}$ of melatonin for $48 \mathrm{~h}$ and western blotting was performed to detect the expression levels of Flag, Septin4, GRP78, GRP94 and cleaved caspase-3. ${ }^{*} \mathrm{P}<0.05,{ }^{* *} \mathrm{P}<0.01$, ${ }^{* * * *} \mathrm{P}<0.001$, vs. NC group. GRP, glucose-regulated protein; NC, negative control; Con, control.

\section{Discussion}

It has been reported that the level of melatonin is associated with IS (37), and the clinical application of melatonin can also be used to treat patients with partial IS, which may be associated with melatonin-induced proliferation and apoptosis in osteoblasts (38). However, the optimal effective concentration and mechanism of action are yet to be elucidated. The present results are in line with those from previous studies, which have reported that low concentrations of melatonin $(1 \mathrm{nM}-100 \mu \mathrm{M})$ promote osteoblast proliferation, while high concentrations of melatonin $(>1 \mathrm{mM}$ ) significantly inhibit osteoblast viability $(15,16,39)$. In order to provide more accurate results, various high concentrations of melatonin $(2,4$ and $6 \mathrm{mM})$ were selected in the present study, and $48 \mathrm{~h}$ was selected as the most suitable observation time to examine melatonin function in osteoblasts, which was based on our previous studies $(40,41)$. In the present study, it was demonstrated that a decrease in 


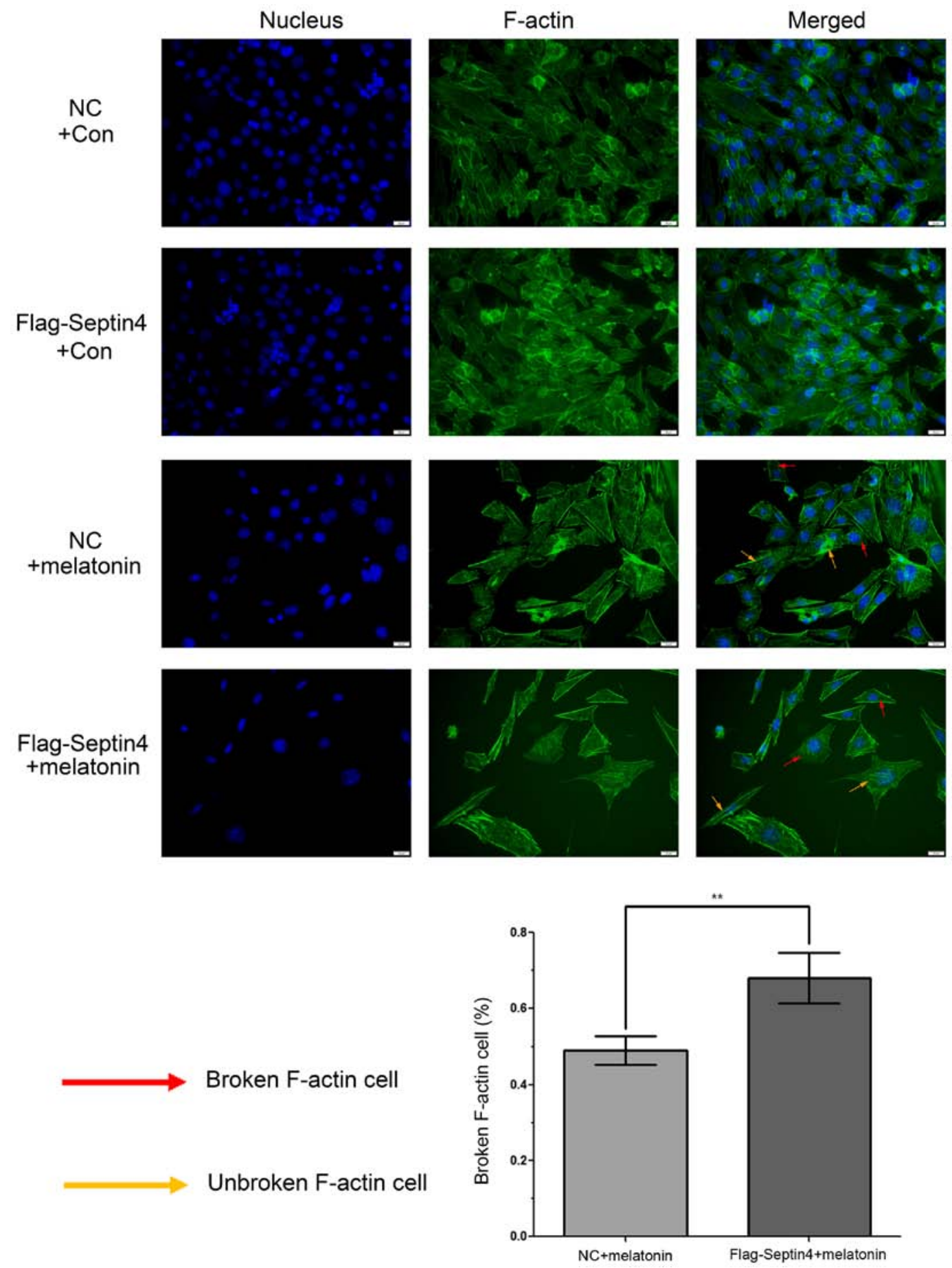

Figure 4. Overexpression of Septin4 increases cytoskeleton destruction in hFOB 1.19 cells treated with a high melatonin concentration. hFOB 1.19 cells were untreated or treated with $4 \mathrm{mmol} / \mathrm{l}$ melatonin for $48 \mathrm{~h}$. F-actin was visualized using phalloidin and the nucleus was stained using DAPI. The images were captured using fluorescence microscopy (x20) and an image of the two stains merged was shown. The yellow arrow represents the F-actin cytoskeleton and the red arrow depicts the destroyed cytoskeleton. The histogram indicates the percentage of cytoskeleton-destroyed cells among the total cells. ${ }^{* *} \mathrm{P}<0.01$, vs. NC group. GRP, glucose-regulated protein; NC, negative control; F-actin, fibrillar actin.

viability of osteoblasts was associated with an increase in melatonin concentration. Furthermore, it was revealed that melatonin induced osteoblast apoptosis via regulation of Septin4, resulting in the promotion of ERS-mediated apoptosis mechanisms involving the GRP94/caspase-3 pathways. This indicates a possible clinical application for melatonin in the prevention and reversal of IS progression.

GRP94 is a member of the HSP90 family and is primarily localized in the ER. GRP94 serves as a molecular chaperone involved in the folding, transport and secretion of proteins, and regulates apoptosis and antigen presentation (42). Furthermore, glucose regulated protein 78 (GRP78) is a core regulator of UPR (43). GRP78 expression is upregulated in ERS, which inhibits protein synthesis and decreases cellular stress in the early stage of ERS. However, prolonged ERS activates the CHOP and caspase-12 pathways, which induce cell apoptosis and result in upregulation of the apoptosis marker protein caspase-3 (44). The present results suggest that 
a high concentration of melatonin induced osteoblast ERS, which was positively associated with melatonin concentration. Furthermore, both of the expression levels of pathway-related genes of ERS (GRP78 and GRP94) and apoptosis (cleaved caspase-3) were significantly increased in a dose-dependent manner of melatonin concentration, which indicates that ERS may serve an important role in cell apoptosis induced by high concentrations of melatonin. However, the target protein by which melatonin induces ERS and cell apoptosis has not been elucidated.

It has been revealed that Septin4, an ER membrane protein and a receptor associated with ERS, inhibits hepatocellular carcinoma via the regulation of hepatoma cell apoptosis (32). Moreover, previous studies have reported that Septin4 aggravates cell apoptosis induced by transforming growth factor- $\beta$, etoposide and staurosporine, and Septin4 affects the regulation of myofibroblast transformation and hepatic fibrosis induced by chemokine ligands $4(32,45)$. Thus, these findings reveal the important role of Septin4 in apoptosis. Furthermore, the present results indicate that increasing melatonin concentration are associated with an increase in the expression levels of Septin4 and ERS-related proteins (GRP78 and GRP94). It was also identified that the expression of the apoptosis-associated protein caspase-3 was positively associated with Septin4 expression, which suggests that Septin4 may regulate bone metabolism via apoptotic pathways. Subsequently, Septin4 was overexpressed and it was demonstrated that melatonin-induced osteoblast injury was further exacerbated, which was indicated by the further decrease in cell viability, apoptotic exacerbations and a significant increase in GRP78, GRP94 and caspase-3 expression levels.

In addition, Septin4 is an important component of the cytoskeleton; thus, phalloidin was used to stain F-actin and DAPI in the nucleus. The present results demonstrated that cytoskeleton destruction, cell morphology changes and the reduction in the number of cells were increased after osteoblasts had overexpressed Septin4 and were treated with melatonin; however, Septin4 did not serve this role independently of melatonin treatment. It was originally speculated that the expression of Septin4 should be increased with $6 \mathrm{mM}$ melatonin,; however, after the repeated experiments, the expression of Septin4 was decreased; this effect may due to the excessive concentration of melatonin, which resulted in enhanced apoptosis and destruction of the cell structure and Septin4 is a cytoskeletal protein, and could not be identified. However, these effects should be investigated in future research. A limitation of the present study was that a Z-VAD-FMK/pan-caspase inhibitor was not used to prevent melatonin-induced Septin4 expression levels. Therefore, further studies are required to investigate the association between Septin4 and apoptosis.

In conclusion, the present results indicated that high concentrations of melatonin may result in ERS and induce osteoblast apoptosis, and that Septin4 is a membrane protein associated with $\mathrm{ER} \mathrm{Ca}^{2+}$ ion regulation and a target for high-concentration melatonin to act on osteoblasts. The present results may provide a novel direction for the treatment of abnormal proliferation of osteoblasts and indicated that suppressing Septin4 may be a novel target for the prevention of IS.

\section{Acknowledgements}

Not applicable.

\section{Funding}

The present study was supported by Natural Science Foundation of Liaoning Province (grant no. 2019-BS-294) and National Natural Science Foundation of China (grant no. 81472044).

\section{Availability of data and materials}

The datasets used and/or analyzed during the current study are available from the corresponding author on reasonable request.

\section{Authors' contributions}

LT, SZha and ZT contributed to the study design, data collection and analysis, as well as the writing of the manuscript. YZ conceived, designed and coordinated the study. KW, SZho and WD contributed to the experimental methods. All authors read and approved the final manuscript.

\section{Ethics approval and consent to participate}

Not applicable.

\section{Patient consent for publication}

Not applicable.

\section{Competing interests}

The authors declare that they have no competing interests.

\section{References}

1. Roach JW: Adolescent idiopathic scoliosis. Orthop Clin North Am 30: 353-365, 1999.

2. Weinstein SL, Dolan LA, Cheng JC, Danielsson A and Morcuende JA: Adolescent idiopathic scoliosis. Lancet 371: $1527-1537,2008$

3. Zhu Z, Tang NL, Xu L, Qin X, Mao S, Song Y, Liu L, Li F, Liu P, Yi L, et al: Genome-wide association study identifies new susceptibility loci for adolescent idiopathic scoliosis in Chinese girls. Nat Commun 6: 8355, 2015.

4. Zhou T, Chen C, Xu C, Zhou H, Gao B, Su D, Liao Z, Li Y, Yang S and Su P: Mutant MAPK7-induced idiopathic scoliosis is linked to impaired osteogenesis. Cell Physiol Biochem 48: 880-890, 2018.

5. Park WW, Suh KT, Kim JI, Kim SJ and Lee JS: Decreased osteogenic differentiation of mesenchymal stem cells and reduced bone mineral density in patients with adolescent idiopathic scoliosis. Eur Spine J 18: 1920-1926, 2009.

6. Zhang J, Chen H, Leung RKK, Choy KW, Lam TP, Ng BKW, Qiu Y, Feng JQ, Cheng JCY and Lee WYW: Aberrant miR-145-5p/ $\beta$-catenin signal impairs osteocyte function in adolescent idiopathic scoliosis. FASEB J: Jun 15, 2018 (Epub ahead of print).

7. Wang WJ, Sun C, Liu Z, Sun X, Zhu F, Zhu ZZ and Qiu Y: Transcription factor Runx 2 in the low bone mineral density of girls with adolescent idiopathic scoliosis. Orthop Surg 6: 8-14, 2014.

8. Qiu S, Tao ZB, Tao L and Zhu Y: Melatonin induces mitochondrial apoptosis in osteoblasts by regulating the STIM1/cytosolic calcium elevation/ERK pathway. Life Sci 248: 117455, 2020. 
9. Aota Y, Terayama H, Saito T and Itoh M: Pinealectomy in a broiler chicken model impairs endochondral ossification and induces rapid cancellous bone loss. Spine J 13: 1607-1616, 2013.

10. Letellier K, Azeddine B, Parent S, Labelle H, Rompré PH, Moreau A and Moldovan F: Estrogen cross-talk with the melatonin signaling pathway in human osteoblasts derived from adolescent idiopathic scoliosis patients. J Pineal Res 45: 383-393, 2008.

11. Man GC, Wong JH, Wang WW, Sun GQ, Yeung BH, Ng TB, Lee SK, Ng BK, Qiu Y and Cheng JC: Abnormal melatonin receptor 1B expression in osteoblasts from girls with adolescent idiopathic scoliosis. J Pineal Res 50: 395-402, 2011.

12. Man GC, Wang WW, Yeung BH, Lee SK, Ng BK, Hung WY, Wong JH, Ng TB, Qiu Y and Cheng JC: Abnormal proliferation and differentiation of osteoblasts from girls with adolescent idiopathic scoliosis to melatonin. J Pineal Res 49: 69-77, 2010.

13. Yim AP, Yeung HY, Sun G, Lee KM, Ng TB, Lam TP, Ng BK, Qiu Y, Moreau A and Cheng JC: Abnormal skeletal growth in adolescent idiopathic scoliosis is associated with abnormal quantitative expression of melatonin receptor, MT2. Int J Mol Sci 14: 6345-6358, 2013.

14. Kono H, Machida M, Saito M, Nishiwaki Y, Kato H, Hosogane N, Chiba K, Miyamoto T, Matsumoto M and Toyama Y: Mechanism of osteoporosis in adolescent idiopathic scoliosis: Experimental scoliosis in pinealectomized chickens. J Pineal Res 51: 387-393, 2011.

15. Liu L, Zhu Y, Xu Y and Reiter RJ: Melatonin delays cell proliferation by inducing G1 and G2 /M phase arrest in a human osteoblastic cell line hFOB 1.19. J Pineal Res 50: 222-231, 2011.

16. Liu L, Zhu Y, Xu Y and Reiter RJ: Prevention of ERK activation involves melatonin-induced $\mathrm{G}(1)$ and $\mathrm{G}(2) / \mathrm{M}$ phase arrest in the human osteoblastic cell line hFOB 1.19. J Pineal Res 53: 60-66, 2012.

17. Xiong XC, Zhu Y, Ge R, Liu LF and Yuan W: Effect of melatonin on the extracellular-regulated kinase signal pathway activation and human osteoblastic cell line hFOB 1.19 proliferation. Int J Mol Sci 16: 10337-10353, 2015.

18. Ellgaard L, Molinari M and Helenius A: Setting the standards: Quality control in the secretory pathway. Science 286: $1882-1888$ 1999.

19. Gething MJ and Sambrook J: Protein folding in the cell. Nature 355: 33-45, 1992.

20. Goodall JC, Wu C, Zhang Y, McNeill L, Ellis L, Saudek V and Gaston JS: Endoplasmic reticulum stress-induced transcription factor, CHOP, is crucial for dendritic cell IL-23 expression. Proc Natl Acad Sci USA 107: 17698-17703, 2010.

21. Kim TJ, Joo C, Seong J, Vafabakhsh R, Botvinick EL, Berns MW, Palmer AE, Wang N, Ha T, Jakobsson E, et al: Distinct mechanisms regulating mechanical force-induced $\mathrm{Ca}^{2+}$ signals at the plasma membrane and the ER in human MSCs. Elife 4: e04876, 2015.

22. Xiang C, Wang Y, Zhang H and Han F: The role of endoplasmic reticulum stress in neurodegenerative disease. Apoptosis 22: $1-26,2017$.

23. Ivanova EA and Orekhov AN: The role of endoplasmic reticulum stress and unfolded protein response in atherosclerosis. Int $\mathrm{J}$ Mol Sci 17: pii: E193, 2016.

24. Li ZR, Yang L, Zhen J, Zhao Y and Lu ZN: Nobiletin protects PC12 cells from ERS-induced apoptosis in OGD/R injury via activation of the PI3K/AKT pathway. Exp Ther Med 16: 1470-1476, 2018.

25. Xiao B,Liu C,Liu BT,Zhang X,Liu RR and Zhang XW: TTF1-NPs induce ERS-mediated apoptosis and inhibit human hepatoma cell growth in vitro and in vivo. Oncol Res 23: 311-320, 2016

26. Li B, He X, Zhuang M, Niu B, Wu C, Mu H, Tang F, Cui Y, Liu W, Zhao B, et al: Melatonin ameliorates busulfan-induced spermatogonial stem cell oxidative apoptosis in mouse testes Antioxid Redox Signal 28: 385-400, 2018.

27. Zha L, Fan L, Sun G, Wang H, Ma T, Zhong F and Wei W: Melatonin sensitizes human hepatoma cells to endoplasmic reticulum stress-induced apoptosis. J Pineal Res 52: 322-331, 2012.
28. Chen Y, Yin H, Tao Y, Zhong S, Yu H, Li J, Bai Z and Ou Y: Antitumor effects and mechanisms of pyropheophorbide- $\alpha$ methyl ester-mediated photodynamic therapy on the human osteosarcoma cell line MG-63. Int J Mol Med 45: 971-982, 2020.

29. Ron D and Walter P: Signal integration in the endoplasmic reticulum unfolded protein response. Nat Rev Mol Cell Biol 8: 519-529, 2007.

30. Sharma S, Quintana A, Findlay GM, Mettlen M, Baust B, Jain M, Nilsson R, Rao A and Hogan PG: An siRNA screen for NFAT activation identifies septins as coordinators of store-operated Ca2+ entry. Nature 499: 238-242, 2013.

31. He X, Bao J, Chen J, Sun X, Wang J, Zhu D, Song K, Peng W, $\mathrm{Xu} \mathrm{T}$ and Duan Y: Adenovirus-mediated over-expression of Septin4 ameliorates hepatic fibrosis in mouse livers infected with Schistosoma japonicum. Parasitol Int 64: 487-492, 2015.

32. Zhu D, Wang J, Sun X, Chen J, Duan Y,Pan J, Xu T, Qin Y, He X and Huang C: Septin4_il regulates apoptosis in hepatic stellate cells through peroxisome proliferator-activated receptor- $\gamma / \mathrm{Akt} / \mathrm{B}$-cell lymphoma 2 pathway. J Histochem Cytochem 63: 163-169, 2015.

33. Shen S, Liu M, Wu Y, Saiyin H, Liu G and Yu L: Involvement of SEPT4 i1 in hepatocellular carcinoma: SEPT4 i1 regulates susceptibility to apoptosis in hepatocellular carcinoma cells. Mol Biol Rep 39: 4519-4526, 2012.

34. Kinoshita M: Diversity of septin scaffolds. Curr Opin Cell Biol 18: 54-60, 2006.

35. Harris SA, Enger RJ, Riggs BL and Spelsberg TC: Development and characterization of a conditionally immortalized human fetal osteoblastic cell line. J Bone Miner Res 10: 178-186, 1995.

36. Subramaniam M, Jalal SM, Rickard DJ, Harris SA, Bolander ME and Spelsberg TC: Further characterization of human fetal osteoblastic hFOB 1.19 and hFOB/ER alpha cells: Bone formation in vivo and karyotype analysis using multicolor fluorescent in situ hybridization. J Cell Biochem 87: 9-15, 2002.

37. Liu H, Liu Z, Man CW, Guo J, Han X, Hu Z, Ng TB, Zhao Z, $\mathrm{Li}$ J, Wang W, et al: The effect of exogenous melatonin on reducing scoliotic curvature and improving bone quality in melatonin-deficient C57BL/6J mice. Sci Rep 9: 6202, 2019.

38. Machida M, Dubousset J, Yamada T and Kimura J: Serum melatonin levels in adolescent idiopathic scoliosis prediction and prevention for curve progression-a prospective study. J Pineal Res 46: 344-348, 2009.

39. Han Y, Kim YM, Kim HS and Lee KY: Melatonin promotes osteoblast differentiation by regulating Osterix protein stability and expression. Sci Rep 7: 5716, 2017.

40. Tao L and Zhu Y: Melatonin regulates CRE-dependent gene transcription underlying osteoblast proliferation by activating Src and PKA in parallel. Am J Transl Res 10: 86-100, 2018.

41. Meng X, Zhu Y, Tao L, Zhao S and Qiu S: Periostin has a protective role in melatonin-induced cell apoptosis by inhibiting the eIF2 $\alpha$-ATF4 pathway in human osteoblasts. Int J Mol Med 41: 1003-1012, 2018.

42. Melnick J, Dul JL and Argon Y: Sequential interaction of the chaperones BiP and GRP94 with immunoglobulin chains in the endoplasmic reticulum. Nature 370: 373-375, 1994.

43. Schröder M and Kaufman RJ: The mammalian unfolded protein response. Annu Rev Biochem 74: 739-789, 2005.

44. Burikhanov R, Zhao Y, Goswami A, Qiu S, Schwarze SR and Rangnekar VM: The tumor suppressor Par-4 activates an extrinsic pathway for apoptosis. Cell 138: 377-388, 2009.

45. Garrison JB, Correa RG, Gerlic M, Yip KW, Krieg A, Tamble CM, Shi R, Welsh K, Duggineni S, Huang Z, et al: ARTS and Siah collaborate in a pathway for XIAP degradation. Mol Cell 41: 107-116, 2011.

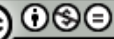

This work is licensed under a Creative Commons Attribution-NonCommercial-NoDerivatives 4.0 International (CC BY-NC-ND 4.0) License. 